from which the $u^{2}$ quantities may be expressed in terms of the $a$ matrix elements. The relation (4) is deducible from eqns. (1) $-(3)$.

In the present case a set of force constants for cyclopropene has been established ${ }^{\mathrm{S}}$ by means of vibrational frequencies taken from literature ${ }^{\circ}$ for both $\mathrm{C}_{3} \mathrm{H}_{6}$ and $\mathrm{C}_{3} \mathrm{D}_{6}$. For the numerical $L$ matrix elements, see Ref. ${ }^{5}$ One of the writers (S. J. Cyvin) intends to give some details of the theory of mean-square amplitude matrices applied to the cyclopropane molecule in a coming publication.

1. Bastiansen, O. and Cyvin, S. J. Acta Chem. Scand. 11 (1957) 1789.

2. Morino, Y., Kuchitsu, K. and Shimanouchi, T. J. Chem. Phys. 20 (1952) 726; Morino, Y., Kuchitsu, K., Takahashi, A. and Maeda, $K$. J. Chem. Phys. 21 (1953) 1927.

3. Cyvin, S. J. Acta Chem. Scand. 11 (1957) 1499; J. Chem. Phys. 29 (1958) 583; Spectro. chim. Acta 15 (1959) 828.

4. Wilson, E. B., Jr. J. Chem. Phys. 7 (1939) 1047; J. Chem. Phys. 9 (1941) 76.

5. Cyvin, S. J. Spectrochim. Acta. In press.

6. Baker, A. W. and Lord, R. C. J. Chem. Phys. 23 (1955) 1636; Mathai, P. M., Shepherd, G. G. and Welsh, H. L. Can. J. Phys. 34 (1956) 1448.

Received May 16, 1956.

\section{A Note on the Crystal Structure of Sodium Dimolybdate}

INGVAR LINDQVIST

Institute of Chemistry, University of Uppsala, Uppsala, Sweden

\footnotetext{
A bout ten years ago the present author carried out a series of structure determinations of polymolybdates, polytungstates, polyniobates and polytantalates. In most cases the proposed oxygen co-ordination around the heavy atoms was supported by some evidence of vectors in the three-dimensional Patterson functions. There were, however, two exceptional cases with very weak or no evidence at all for the oxygen positions which were aissumed from spatial discussions. In one of these cases, $\mathrm{MoO}_{3} \cdot 2 \mathrm{H}_{2} \mathrm{O}$, the presence of a complicated superstructure has later been shown 1 .

The other case is sodium dimolybdate ${ }^{2}$. The molybdenum positions were conclu-
}

sively derived but the oxygen co-ordination proposed was based on the assumption that the co-ordination around the molybdenum atoms should be either tetrahedral or octahedral. As the resulting structure exhibited an interesting mixed co-ordination an attempt has been made to derive the oxygen positions directly from the three-dimensional Patterson function using the Buerger minimum function ${ }^{3}$.

This derivation has confirmed the structural suggestion of the earlier paper. The positions of the oxygen and sodium atoms are, however, shifted to some extent. The old data do not permit a refinement with modern methods and the atomic positions are therefore still very uncertain. The following rough parameters give a $R$ value of 0.17 (the old parameters within brackets):

$$
\begin{aligned}
& 8 \mathrm{Mo}_{\mathrm{I}} \text { in } 8(e): x=0.25 \\
& 8 \mathrm{Mo}_{\text {II }} \text { in } 8(f): x=0.00 \\
& 8 \mathrm{Na}_{1} \text { in } 8(d): x=0.25 \\
& 8 \mathrm{Na}_{\text {II }} \text { in } 8(f): x=0.00 \\
& 16 \mathrm{O}_{\mathrm{I}} \text { in } 16(g): x=0.18(0.21) \\
& 16 \mathrm{O}_{\mathrm{II}} \text { in } 16(g): x=0.18(0.21) \\
& 8 O_{\text {III }} \text { in } 8(f): x=0.00 \\
& 8 \text { OIV in } 8(f): x=0.00 \\
& 8 \mathrm{Ov} \text { in } 8(f): x=0.00 \\
& y=0.08 \\
& y=0.25 \\
& y=0.00 \\
& y=0.31 \quad(0.36) \\
& y=0.22(0.21) \\
& y=0.48(0.49) \\
& y=0.11(0.08) \\
& y=0.38(0.41) \\
& y=0.37(0.35) \\
& \begin{array}{l}
z=0.25 \\
z=0.08 \\
z=0.00 \\
z=0.36(0.30) \\
z=0.17(0.16) \\
z=0.33(0.34) \\
z=0.28(0.27) \\
z=0.02(0.13) \\
z=0.52(0.49)
\end{array}
\end{aligned}
$$

The proposed mixed tetrahedral and octahedral co-ordination around the molybdenum atoms can be considered as strongly supported by this result. The relatively low $R$ value by no means proves, however, that the atomic positions are well determined, as the contributions from the Mo atoms are too dominating. A further discussion of the bond lengths on the basis of these rough parameters therefore cannot be recommended.

1. Lindqvist, I. Acta Chem. Scand. 10 (1956) 1362.

2. Lindqvist, I. Acta Chem. Scand. 4 (1950) 1066.

3. Buerger, M. J. Vector Space, Wiley, New York 1959.

Received May 30, 1960. 